Andries Wessels

Andries Wessels is professor en hoof van die Departement Engels aan die

Universiteit van Pretoria.

E-pos: andries.wessels@up.ac.za

\section{Intertekstualiteit en modernistiese kompleksiteit in Henriette Grové se Linda Joubert-romans}

Intertextuality and modernist complexity in Henriette Grové's Linda J oubert novels.

Henriette Grové debuted in 1947 as an author of popular stories in women's magazines under the pseudonym Linda Joubert. Meulenhof se mense and Die laat lente appeared in the nineteen-fifties in Sarie Marais and were published in book form in the early nineteen-sixties. Although the author expressed her opposition to an evaluation of these popular romantic tales as part of her literary oeuvre, the two novels reveal a surprising complexity and density as regards both content and narrative structure which strongly link them in theme and technique to her recognized literary oeuvre, so that the two novels emerge as worthy literary texts in their own right after all, while they clearly function within the conventions of the genre of the romance novel. The novels also reveal an impressive range of sophisticated literary allusions which further characterize them as modernist. Key words: Afrikaans popular literature, Henriette Grové, intertextuality, modernism.

Die veel bekroonde Afrikaanse prosaïs en dramaturg, Henriette Grové, wat onder andere dieHertzogprys in al bei hierdiekategorieëverwerf het - in 1981 vir dramaen in 1984 vir prosa - het in 1947 onder die skuilnaam Linda Joubert as skrywer van populêretydskrifverhale gedebuteer (Roos 1998: 48). Twee van die Linda Joubertverhalewat in dievyftigerjarein dieSarieM arais-vrouetydskrif verskyn het, $M$ eulenhof semense (1956) en D ielaat lente(1957), het in dievroeësestigerjarein boekvormverskyn. 'n Keur van dietydskrifkortverhaleis ook onder dietitel Roosmaryn en wynruit (1962) onder dienaam LindaJoubertuitgegee. M eulen hof semense isverder in diesestigerjare as radioverhaal uitgesaai en uiteindelik in 1980 deur Stephan Bouwer vir televisie verwerk (Van N iekerk 1999: 412). Dietwee romans is in onderskeidelik 2008 en 2009 deur Human \& Rousseau heruitgegeeen isna vyftig jaar weer goed ontvang. Joan Hambidge (2008) prys byvoorbeeld M eulenhof se mense op LitN et en sê "dit bly 'n lofwaardigeteks: beheerst geskryf en met subtieletoespelings op diekonvensies van sowel dieliefdes- as belydenisroman". Hambidgesekommentaar dui daarop dat ons hier met' $n$ gesofistikeerdetoespeling op dieliefdesverhaal tedoen het, eerder as met bloot'n konvensioneleliefdesverhaal self, sooswat dieLinda-Joubert-romansdikwels voorheen aangeslaan is (vgl. bv. Cilliers 2009). 
Dievolgehoue propagering van dietweetekstein hulleverskillendeverwerkings onder dieoorspronklikeskuilnaam sedertM eulenhof semense in 1956astydskrifverhaal verskyn het, het natuurlik'n historiese basismaar dui ook op 'n keusevan dieskrywer self om diewerkenieas deel van haar veel bekroondeliterêreoeuvreteag nie, maar as newewerk van "mindere" literêregehalte. In 'n gesprek metElizeBothain 1973verklaar Grovédat sy dieverhale "louter om den brode" geskryf het en druk haar teenkanting daarteen uit dat daar oor die waarde en "plek" van hierdie verhale in haar oeuvre bespiegel word (Botha 1973: 61). In weerwil van dieskrywer se eievoorbehoudewil ek egter voorstel dat wanneer dietweetekstevan naderby beskou word hulleal bei 'n verrassendekompleksiteit en digtheid beideten opsigtevan inhoud en narratiewe tegniek openbaar. Tematies en tegnies hou die romans nou verband met Grovése erkendeliterêre oeuvreen onderskei hulleas waardigeliterêrewerkein eiereg al is dit dan binnediebepaaldegenre-konvensiesvan dieliefdesverhaal. Selfsin 1973 was daar steeds- veral in Afrikaans- 'n onoorbrugbare kloof tussen wat Elize Botha in die gesprek "hogere literatuur" (1973: 59) noem en populêre verhale en dit verklaar waarskynlik die skrywer se onwilligheid in daardie stadium om hierdie werke in dieselfdeasem as haar veel bekroonde oeuvre te noem. Henriette Roos (1998) plaas Grovésehoofstroomwerk in 'n modernistieseraamwerk en konstateer: “beplande vormgewing en die verinnerliking van gebeure bepaal die verhaalstruktuur. Die veel vlakkigevertel perspektief, dieverstrengel de en bewussynsbeelding, dieuiters hegtestrukturering van herhalende beel deen motiewe waardeur dievertelling ' $n$ besonder digtesamehang en veelvlakkige betekenislaag vertoon, is tipies van haar styl" (69-70). Na my mening is hierdiekensketsing eweneens toepaslik op dietwee LindaJoubert-romans asop Grovése meer bekendeen bekroondewerk. Watmeer is, dieromans getuig van 'n verrassendewyespektrum van literêreverwysings, 'n tegniek wat integraal is aan diemodernistiesewerkswyse, in sommige gevallemoontlik tongin-die-kies toegepas, en in die besonder na beideliterêreen populêrewerkein die negentiende-euseen vroeëtwintigste-euseAngel-Saksiesewêreldletterkunde. Die toespelings op klassieke en populêre Engelse letterkunde is van 'n besondere gesofistikeerde aard en dra grootliks by tot die literêrekompleksiteit van dietekste. Die eggo's van die romanskryfster-susters, Emily en Charlotte Brontë is besonder interessant en insiggewend. Piet Roodt verklaar na Grovése dood in 2009 teenoor Beeld dat Grové "dieDuitse, Engelseen Amerikaanseletterkundegeken [het] en alles gelees[het] waarop sy haar handekon lê" (Rademeyer 2009).

M eulenhof semense (wat in 1961 in boekvorm verskyn het) is'n briefroman. Dit is nie die eerste briefroman in Afrikaans nie. Die eerste belangrike voorbeeld is waarskynlik Langenhoven seSkaduw ees van N asaret (1927) (vgl. Botha 1987: 151-52), hoewel Kannemeyer (1965: 126) dit "nouliks ... 'n roman" noem en eerder M. E. R. se novelle "Goedgeluk" wat ook in 1927 in haar eerste bundel 0 nweer shoogte en ander verhale verskyn het, as "verreweg die belangrikste voorbeeld" uitsonder. Hy noem 
ook Sy kom met diesekel maan (1937) van HettieSmit, A an Jannie (1945) van dieH obsonbroers, Van Willem en San (1947) deur Anna Heymans (skuilnaam vir Anna NeethlingPohl en W. A. de Klerk), Mikro se novelle "Liewe (Beste) Maans" in D ie houtswaan (1954), en inderdaad M eulenhof semenseas voorbeelde (1965: 126). Annievan Niekerk [later Schumann] se M et liefdevan K atinka het verder in 1946 verskyn (Van N iekerk 1999: 355, 370). Hoewel diebriefroman sy oorsprong reeds so vroeg as die 15deeeu het en as gesofistikeerde literêre vorm in dieagtiendeeeu sterk na voregetree het met beroemdevoorbeelde deur onder andereSamuel Richardson in Engels, Jean-Jacques Rousseau in Frans en Johann Wolfgang von Goethein Duits, herinner dieaanslag in M eulenhof se menseeerder aan twee populêre briefromans wat in dievroeëtwintigste eeu in Engelsverskyn het, D addy-Long-Legs (1912) van dieAmerikaanseskryfster, Jean Webster (waarvan 'n Afrikaanse vertaling deur W. O. Kühne, Vadertjie L an gbeen, in 1958 as deel van J. L. van Schaik se Libri-reeks verskyn het), en Anne of Windy Willows (1936) van die populêreKanadeseskryfster, L. M. Montgomery. In al bei gevalleis die briefskryfsters jong meisies wat uit 'n nuwe omgewing briewe skryf waarin hulle hulle belewenis van hierdie omgewing (op 'n vermaaklike en taamlik lughartige wyse) weergee. Laasgenoemdeomstandigheid is volgens Kannemeyer (1965: 127) en Botha (1987: 150) 'n tipiese gegewe vir diebriefroman. Veral dieverteller van A nne of Windy Willows, wat deel uitmaak van dieAnne of Green G ables-reekstoon aansienlike ooreenkomste met die verteller, Annemarie Herbst, in $M$ eulen hof se mense. Albei is jong onderwyseresse wat op 'n klein dorpiegaan skool hou en by oujongnooidames of weduwees in groot wonings wat van vervloëgloriespreek, tuisgaan. Hoewel die Montgomery-teks deurgaans lughartig is en niediegeladedrama van M eul enhof se mense weerspieël nie, is dit nie slegs sekere stylooreenkomste wat die verwysing bevestig nie; daar isook 'n direkteverwysing na dieKanadeseteks in dieAfrikaanse roman. Annemarie Herbst hef haar briewe aan haar verloofde, Jan, 'n teologiese student, gewoonlik aan met diebegroeting "My liewe Jan" of "My liefsteJan" of net "My liefste". Op 28Februarie 1904 begin sy egter 'n brief uit Meulenhof so:

My seergeagte en toegeneë heer Marais,

Aangesien ek deesdae gedurig besig is met die dinge wat lankal verby is, moet jy maar vir lief neem dat ek my brief so begin... Ek hou veral van die toegeneë. Die dametjie wat dertig jaar gelede haar brief so sou begin het, het natuurlik nog 'n stywe hoepelrok gedra, met sulke sypantoffeltjies en strikkies wat op allerhande plekke uitgesteek het. En hier sit ek nou in ' $n$ vervelige boeselromp met oninteressante plathakskoene. Nee wat, Jan, die wêreld was darem veel meer romanties... (63).

En op 10 Oktober van omstreeks 1919, skryf diejong onderwyseresAnneShirley wat haar verloofde, Gilbert Blythe, 'n mediesestudent, normaalweg aanspreek as “Gilbert Dear" of "Dearest" vanaf diehuisWindy Willowsop PrinceEdward Island in Kanada: 
Honoured and Respected Sir,

That is how a love-letter of Aunt Chatty's grandmother's began. Isn't it delicious? What a thrill of superiority it must have given the grandfather (Montgomery 1949:

24).

En op 5Januariehef sy ' $n$ verderebrief so aan:

My Esteemed Friend,

Thisis't anything Aunt Chatty's grandmother wrote. It's only something shewould have written if she'd thought of it (Montgomery 1949: 142).

Dit is duidelik datGrovédieselfdekomiesetruuk van dieverouderdeaanspreekvorm as M ontgomery gebruik, maar sy maak veel meer van diekwinkslag. Grovégebruik diéinleiding om Annemarieseemosionele betrokkenheid by dieverledeen derhalwe dievroeëredramatiesegebeureop Meulenhof tebeklemtoon. Hierdiepreokkupasieis een van diehoofredes vir diegedetailleerdebrieweoor dieuitpluising van dieverlede op Meulenhof, wat dieverteller aan haar verloofdeskryf en wat dieliggaam van die teks uitmaak. Daar is natuurlik ook 'n aantreklikeironieaan diefeit dat diekarakter Annemariehaar in dieglans van dieverledeteenoor haar eiealledaagse "moderne" bestaan in 1904verlustig, terwyl die1956- of 1961- (of 2008)-leser van M eulenhof semense weer dieverglinstering van die1904-verledemet' $n$ hoogsverfyndeal is dit bedreigde lewenstyl gekenmerk deur herehuise, balrokkeen silwerware- waarop dieskryfster baie doelbewusinspeel - eweneensas ouwêreldsen bekoorlik geniet.

Hoewel Grovévolgens haar eiebekentenis dieverhalevir'n populêreleserspubliek geskryf het, funksioneer sommige van die literêre verwysings op klassieke modernistiese wyseom betekenisteverleen - vir daardielesers wat diemeer literêre verwysings in wat skyn om bloot'n populêreliefdesverhaal tewees, wel identifiseer. In D ielaat lente beskryf diejong dogter, Fleurette, wat'n obsessiemet haar oorledema en diéseskoonheid het, hoesy haar courtisane-sangeres-ma gehelp het wanneer sy haar pragtig aangetrek hetom manstebetower: "Ek hethaar harevir haar gekamvoor sy hulle opgesteek het. In die donker het die borsel klein vonkies daaruit geslaan" (27). Gesien die konteks, is dit 'n baie waarskynlike verwysing na die Britse digter T. S. Eliot se ikoniesemodernistiesegedig TheW aste Land (1922):

Under the firelight, under the brush, her hair,

Spread out in fiery points

Glowed into words, then would be savagely still (Eliot 1969: 64-65).

DieW aste Land-karakter waarna hier verwys word is die Belladonna-figuur in die tweede gedeelte, "A Game of Chess." Haar naam beteken "skone dame" in I taliaans, maar isook dienaam van 'n uiters giftige planten al bei hierdie betekenisseistoepaslik op die histeriese figuur in dieversmorende, oorversierdemilieu wat in diegedeelte 
beskryf word. Eweneens is albei die betekenisse van skoonheid en vergifting verhelderend ten opsigte van GrovéseFranse courtisane, Agnete Moir, in D ielaat lente.

Origens is daar ' $n$ belangrike intertekstuele toespeling op Charlotte Brontë se klassiekeVictoriaanseroman, J aneEyre(1847) in hierdiewerk. N et soosJean Rhys die ondergeskikte gegewe van die verhaal van BerthaAntoinetteMason, Rochester se eerstevrou in JaneEyre, tot sentralegegewein haar 1966-roman, Wild Sargasso Sea (wat in eiereg 'n klassiekemodernewerk geword het) verhef, neem Grovédienog kleiner gegewevan dieverhaal van CélineVarens, Rochester seminnares en haar dogter van onbekende vaderskap, Adèle, wat in sy voogdyskap beland en bou daarop haar verhaal. (Let wel datD ielaat lentevóór Wild Sargasso Sea verskyn het en Grovédusnie deur Rhysseontlening beïnvloed kon geweeshet nie.) Aangesien sy dieverhaal in 'n Afrikaansemilieu verplaas, word diekaraktersen omstandighededienooreenkomstig getransformeer, maar dieintertekstuel everwysings is onomwonde. Agnete Moir is kwansuis'n sangeres soos Céline Varens'n danseres is, maar in werklikheid is al bei courtisanes wat hulle lewe maak uit die "borgskap" van onderskeie minnaars in Parys in Frankryk. Sy het ' $n$ afhanklike dogtertjie, Fleurette, net soos Céline se dogtertjie, Adèle. Sy ontmoet ' $n$ welgestel delandheer, J ohannes van Brakel van die Kaapkolonie, net soosCélineVarens'n welgesteldeEngelselandheer, Edward Fairfax Rochester, ontmoet, en gaan onder sy "beskerming". Albei is ontrou aan hulle beskermhereen gaan voort om ander manstevermaak. (Anders as Rochester in die permissiewegemeenskap van diemid-negentiende-eeuse Parys, trou Johannes van Brakel in die meer behoudende gemeenskap van die eind-negentiende-eeuse leefwêreld van dieKaap, met Agnete. Getrou aan tradisionele persepsies van die metropool en diekoloniale wêreld, is Johannes ook 'n meer onskuldige en naïewe karakter as diegesofistikeerdeen ervare Rochester.) Albei vrouelaat hullekinders in die sorg van hul minnaars agter. In albei gevalle word 'n oënskynlik sobere en nie baieaansienlikegoewernante (Jane Eyrein diegelyknamige roman en LinaOp't H of in D ielaat lente, albei weeskinders wat onder moeilikeomstandighedegrootgeword het) in diens geneem om die dogtertjie te versorg en ontwikkel daar 'n liefdesverhouding tussen diewewenaar en diegoewernante wat onder diesobere uiterlike'n uiters hartstogtelikeinnerlikeverberg. GrovéseAgneteweerspieël egter ook sekere aspekte van Rochester se waansinnige vrou, Bertha (wat later die hoofkarakter in Rhys se roman sou word) deurdat Grové'n kolonialeelement aan Agnete se agtergrond verleen (deur die onheilspellende "geel" Franssprekende oppasster en bediendeuit Noord-Afrika, Josephine) asook ten opsigtevan dieaspek dat dit die ontgogeldelandheer seeggenote (eerder as sy minnares) is, wathom baie ongelukkig gemaak het en wat 'n skadu oor dienuwe verhouding gooi. Op hierdie intertekstueleverwysing bou Grovéhaar eieverhaal met'n eiesoortige dinamiek en vind die "vormgewing" en "verinnerliking van gebeure", die "uiters hegte struk- 
turering van herhalende beel de en motiewe waardeur die vertelling ' $n$ besonder digtesamehang en veelvlakkigebetekenislaag vertoon" plaas(kyk Roos 1998hierbo). Soos altyd skep Grové'n betekenisvollesielkundige milieu en D ielaat lente isveral 'n verhaal oor skuld en kwytskelding en oor die bevrydingsrol van die liefde binne hierdie konteks. Joan Hambidge (2008) noem dat M eulen hof se mense hom leen tot psigoanalitiesediskoerseweens dieaanwesigheid van bekendesimbolesoos diemaan, die spieël, die huis (eerder gevangenis)...", en al hierdie gegewens is eweneens toepaslik op die tweede Linda J oubert-roman, waar verder ook die ingewikkelde Freudiaansevervlegtingsvan diegeladeouer-kind-verhouding (beidemetverwysing naFleuretteen naJ ohannes van Brakel self) onder dieloep geneem word.

Soos die titel aandui, is die seisoene een van diesimbool-siklusse waarmee die skryfster in dieroman werk. Dit sluit aan by verderenatuursimbool patrone, wat veral voëls en blomme betrek, voorbeel de van herhalende "beeldeen motiewe" wat die vertelling verryk en wat dit ook uitlig bo gewone verstrooiingsliteratuur. Kleding, vuur en storms, asook 'n kompleksespel met beeld en refleksiewat hoofsaaklik met skilderyeen spieëlswerk, vorm verdere simbool patronein D ielaat lente.

Aanverwant aan die drogbeeldeen weerspieëlings vorm dietema van waarheid en leuen, of "syn en skyn" soos EnaJoostedit in haar verhandeling (1975) oor hierdie element in Grové se werk noem, 'n belangrike draad in D ie laat lente. In Grové se erkende oeuvre staan dietema van waarheid en leuen byvoorbeeld sentraal tot die kortverhaal "Die Bethlehem-ster" (wat in dieselfde tyd perk as die Linda Joubertromans in 1957 as een van dieverhale in K wartet (saam met bydraes van M. E. R., Ina Rousseau en Elisabeth Eybers) verskyn het en later ook in Jaarringe[1966] opgeneem is), en die novelle D ie kêrel van die Pêrel (1983) wat allerweë as een van Grové se belangrikstewerkebeskou word en waarvoor sy inderdaad dieHertzogprysverower het. Met verwysing na diewaarheid- en leuen-tema in Grovésewerk, verklaar Heilna du Plooy: "Hierdiebemoeienis met waarheid en leuen, dieheledilemma rondom die onversoenbaarheid en ononderskeibare gedaantesvan syn en skyn bly dwarsdeur Grové se oeuvre prominent en die problematiese aard van etiese kwessies word al gaande al hoe skerper gedefinieer" (Du Plooy 1998: 478). Henriette Roos skryf eweneensop 10Desember 1989in Rapport (naaanleiding van Grovéselaasteroman In diekamer was'n kas):

Die spieël- en musiekmotiewe verbeeld nie net hóe die vertelling plaasvind nie, maar ook waaróm dit eintlik handel. Albei beelde impliseer die bestaan van 'n werklikheid vol paradoks en teenstelling, ' $n$ bestaan waarin kontrasterende visies mekaar relativeer maar ook met mekaar vervloei (aangehaal in Van Niekerk 1999: 412).

In D ielaat lente probeer Lina, wat as kind "nooit diewaarheid verdraai [het] nie" (31), in dieloop van dieverhaal om diewaarheid omtrent diegeskiedenisvan Johannes, 
Agneteen Fleurettetepeil: “Diewaarheid, diemoet tog ook hier op Schoonaanzicht wees, hier op die pragtige plaas wat so ruim tussen die rivier en die kranse van die bergeagter lê" (69). Die meeste karakters klou egter vir hulleeiedoeleindes of hulle eie of ander se beskerming aan droom- of drogbeeldevas, sodat die "waarheid" Lina - en dieander karakters- grotendeels bly ontwyk. Daar is verskeieverwysingsnadie probleem watkarakters soos Lina (79) en Mevrou Buitendacht, dievroedvrou (67), het om diewaarheid teenoor hulleself teerken. Agneteword byvoorbeeld verder obsessief deur haar dogter verafgood as ' $n$ beeldskone sangeres, ' $n$ beeld wat Fleurette aan almal voorhou, maar deur ironieseontboeseming in diestyl van Jane Austen openbaar juis Fleurette haar ma as in werklikheid 'n gewetenlose jagter van mans wat haar minnaarsuitbuit vir geld en juw ele, maar hulleagter hullerûebespot (40-42). ${ }^{1}$ Intussen bedryf Agnetehaar eieverslaafdeobsessiemet die dobbelaar-gigolo en klaarblyklike psigopaat PierreGarceau. Fleuretteweier om hierdieverslawing van haar mateerken en bewustelik te deurgrond, maar in 'n komplekse spel van ontkenning en bevestigendeinstink, van syn en skyn, gedryf deur haar obsessiewejaloesieop haar ma, probeer sy Garceau uit die weg ruim, 'n daad wat ironies tot haar moeder se (vir haar) tragiese dood lei. Die plaas en herehuis senaam, "Schoonaanzicht", speel ook in op die tema van waarheid en leuen: 'n skone en ordelike aansig verskuil die donker emosioneel-chaotieseen onderdruktepsigieseen historiese werklikheid (en waarheid) ten opsigte van dieplaasseinwoners.

Soos Charlotte Brontë in Jane Eyre, maak Grové ook van 'n sterk Gotiese inslag gebruik om 'n gevoel van broeiende onheil vir die leser te skep. Gedurige voorgevoelens van onheil, plekbeskrywings gekenmerk deur donker en skadu (11), diedreigendeteenwoordigheid van dieenigmatiese Josephinewat geen ooghare of wenkbroue het nie (15), drogbeelde in die spieëls in die opstal (22-23) en grafbeskrywings (33) skep 'n dreigende Gotieseatmosfeer wat "donker en vol vrees" (37) is in uittreksels soos dié:

Dan hoor sy iemand nader kom, en dit is vir haar of al die dinge waarvoor sy bang was op Schoonaanzicht: die lang skaduwees van die grafsteen, die vreemde glans van ' $n$ portret, die skittering van ' $n$ vrou se smaragde, ' $n$ hele ongelukkige verlede een word met die voetstappe wat nader kom. Sy druk die papier teen haar bors en draai haar kop met groot wilsinspanning (109).

Ook feëverhaal-elemente, veral heksagtigefiguresoosJosephine(90) en dievroedvrou (64) dra by tot die atmosfeer van Gotieseonheil. Hoewel dietemavan onheil relevant tot dieverloop van dieverhaal isten opsigtevan dieverskuildehartstogteen donker gebeure wat Lina moet ontsluit alvorens sy geluk by Johannes van Brakel sal kan vind, word dit ook - soos dikwels in die Gotiesetradisie- deur die skryfster gebruik bloot om diespanningslyn teversterk en 'n plesierige frisson van opwinding aan die leser teverskaf. 
Kannemeyer vermeld Rebecca (1938), Daphnedu Maurier seklassiekeliefdesverhaal met 'n sterk Gotiese inslag, as 'n bron vir D ie laat lente en noem laasgenoemde "'n roman wat meer astoevalligeooreenkomstetoon met Du Maurier se Rebecca" (1983: 327). In al bei gevalle word ' $n$ wewenaar se eerste ongelukkige huwelik met ' $n$ beeldskone, losbandige vrou inderdaad ' $n$ bedreiging vir ' $n$ volgende gelukkige verhouding met ' $n$ minder verleidelike vrou met heel wat meer integriteit. Albei verhale speel in herehuiseaf waar dieverledeonheilspellend inspeel op diehede. Kannemeyer meld egter nie dieveel belangriker verwysing naJ aneEyrenie. JaneE yreword wyd as 'n belangrikebron vir Du Maurier se R ebecca beskou (vgl. bv. Yardley 2004: C01). Dit is dusheel moontlik dat dieBrontë-roman asoerteks vir al bei dietwintigste-eeusetekste gedien het, sonder dat daar noodwendig onderlinge beïnvloeding is. Die afbrand van dieherehuisManderley aan dieeindevan R ebecca toon eerder ooreenkomstemet gebeure in M eulenhof semenseasmet $D$ ielaat lente.

Soos gemeld, ontleen die karakterisering van Lina Op 't H of en Johannes van Brakel ook in 'n mateaan diekaraktersJaneEyreen Edward Fairfax Rochester. Van Brakel gaan gebuk onder geweldigeskuldgevoelensen het diep gely onder diegedrag van sy vrou, Agnete, net soos Rochester diep gely het uit die huwelik met die waansinnige Bertha waarin hy as jongeling deur dietweefamilies verkul en verstrik is. Rochester voel dat sy verhouding met Jane Eyreas vergoeding vir sy lyding mag geld: "After a youth and manhood passed half in unutterable misery and half in dreary solitude, I have for the first time found what I can truly love- I have found you." (Brontë2007: 312) en Van Brakel spreek soortgelykegedagtesoor sy verhouding met sy eievaal goewernante uit: “Weet jy wat het ek gedink die aand toejy gekom het? Dat ek miskien nou lank genoeg geboet het, dat die skuld uitgewis is. Ek het gedink ek sou nuut kon begin, saam met jou" (78). Van Brakel noem Lina sy "klein, grys duifie" (127) en Rochester gebruik ook dikwels voëlbeel deom Janetebeskryf (bv. Brontë2007: 251, 307, 309).

$M$ eulenhof se mense is ongetwyfeld ' $n$ meer komplekse roman as $D$ ie laat lente. Hoewel dit ook in gesprek treemet dienegentiende-eeuse Engelseletterkundeis die interaksiemeer kompleks en genuanseerd as in dietweede LindaJoubert-roman. So herinner dieveelvlakkigenarratiewetegniek in M eulenhof semensesterk aan Emily Brontë se narratiewe strategieë in Wuthering H eights (1847). Die hoofverteller in M eulenhof semense is diejong onderwyseres wat diegebeurein brieweaan haar kêrel, Jan, ' $n$ teologiesestudent op Stellenbosch, weergee. Hierdie primêrenarratief loop vanaf 1 Februarietot 15 Maart 1904, dus'n relatief kort tydsverloop na aan dieeinde van die verhaal as sodanig. Die ooreenstemmende primêre narratief in Wuthering H eights is diedagboekvertelling van ene Lodkwood, wat in 1801 as'n huurder van die herehuisThrushcross Grangein diebetrokkebuurtopdaag. Daardieprimêrenarratief strek van 1801 tot 1802, ook - in diebestek van dieverloop van dieverhaal oor meer as veertig jaar - 'n relatief kort tydjie, na aan dieeindevan diebetrokkegebeure. Vir die 
grootstedeel van dieboek word Lockwood seraamvertelling gevul deur 'n tweedevlak-narratief, diévan N elly Dean, wat haar hele lewe by dieEarnshaw-familievan Wuthering H eights en die Linton-familievan Thrushcross Grange betrokke was en in al bei huise as huisbediende gewerk het. Sy verskaf dus die meer gedetailleerde gegeweoor ' $n$ langer tydperk wat ook diegrootste deel van dieboek beslaan en kan dus in hierdiesin as die belangriksteverteller in Wuthering $\mathrm{H}$ eights gereken word. Sy gee op haar beurt egter ook stories weer wat sy eerstehands by H eathcliff, I sabella Linton, Catherine Earnshaw en die bediendeZillah hoor (dus derdevlak-narratiewe, vervat in N elly se relaas en dan hervervat in Lockwood seraamnarratief). Dieeffek van hierdievervlegting van narratiewe is dat dieleser ' $n$ (onrealisties-)gedetailleerde herbelewenis van die gebeure ervaar, grotendeels oorgedra deur aksieen dialoog, gekommunikeer deur personeten nousteby diegebeurebetrokke, met'n gevoel van onmiddellikheid eerder as diebelewenisvan dietweede- of derdehandseoorvertelling wat dieraamnarratief in werklikheid is.

AnnemarieHerbst is dus Lockwood seeweknie; soos hy issy 'n buitestander wat met groot nuuskierigheid diegebeureop Meulenhof tydens haar verblyf sowel as die vroeëre gebeure wat tot die spanninge tydens haar verblyf aanleiding gegee het, probeer peil. Annemarie se briewe vervul dieselfde rol as Lockwood se dagboek, maar weer eens is dit die basis vir ' $n$ baie meer komplekse narratiewe struktuur: ingesluit in Annemariese brieweis (tweedevlak-) narratiewe deur ander karakters soos die susters Pauline en N ellie Vermeulen (is die naam Nellie dalk ' $n$ speelse leidraad?), diebuurman Malan du Toit, dievoormaligestalkneg Bill Potgieter en die dorp seskinderbek, mevrou Rachel van Staden (wat soms op hullebeurt oordra wat ander aan hullevertel het, sodat daar ook implisiet derdevlaknarratieweis). Soos die narratiewein Wuthering $\mathrm{H}$ eights word dieverhaal in groot deurleefde besonderheid oorgedra, sodat dieleser al diegegewens asof eerstehands beleef. Kannemeyer maak beswaar teen Grové se narratiewe strategie in dié roman en verklaar dat "die onthullingstegniek diegevolg het dat haas elkekarakter tegemaklik inligting verskaf en 'n prater word, terwyl diebriefskryfster self methaar afluistery en uitvraery teveel 'n blotenuuskierigeagiebly" (1983: 326). Hierdiekritiek sou egter ook op dieklassieke Wuthering $\mathrm{H}$ eights toegepas kon word, waar N elly Dean se besonder gedetailleerde vertelling juis deur Lockwood senuuskierigheid ontlok word.

Soosin Wuthering H eights, is Grovésegebruik van chronologieen tyd in M eulenhof se menseeweneenskompleks. Annemarievergelyk self haar narratiewetaak met die bou van 'n legkaart, met verwysing na' $n$ tyd toesy as kind lank siek was:

Daardie selfde middag het ek begin bou. Die gondelroeier was eerste. Dit was eers die kantstukkies, almal so langs mekaar op die skinkbord. En toe begin die groot gesoek na die res: die water en die boot en die bootman.

En nou wil jy weet waaromek oor ' $n$ snipperprent keuwel. Ek was so lief daarvoor, Jan, en selfs vandag nog hou ek van die hapgesnyde vormpies wat so deurmekaar 
geskommel in hulle dose lê. Meulenhof en drie susters, ' $n$ bruidsrok van vyftien jaar gelede en 'n groot man met ' $n$ vlammende baard, 'n krygsgevangene uit Bermuda - vae aanduidings, skemerige verwysings! Wat sou dit alles beteken? lewers moet daar dinge wees wat sluit. Jy moet maar geduldig soek en pak (34).

Op byna postmodernistiese wyseverskaf Grovédus'n metafoor vir haar narratiewe tegniek en diestruktuur van dieroman. Dieverhaal word niechronologies vertel nie, maar brokkies inligting oor verskillende aspekte en uit verskillende fases van die gegeweword algaandeingevul terwyl dielaastefasevan dieverhaal van Februarie tot Maart 1904 voltrek word, totdat die leser ' $n$ volledig prent aan dieeindeaanskou, soos' $n$ voltooidelegkaart. Net soos Lina in D ielaat lente, soek Annemarie Herbst ook na diewaarheid, diehistoriese waarheid oor gebeure by Meulenhof, maar ook die sielkundigewaarheid agter diekaraktersseoptredeen besluite. Maar soos Lockwood in Wuthering H eights issy 'n relatief onbetrokkeverteller, hoofsaaklik gemotiveer deur nuuskierigheid oor die rare gebeure, eerder as' $n$ betrokkerolspeler in dieintrigeself. Interessant maak Kannemeyer ook beswaar teen die narratiewetegniek in D ielaat lenteen verklaar: "Alhoewel die ontknoping vernuftig is, het ' $n$ mens diegevoel dat diehandeling teveel op dieverledegekonsentreer word en dat diegeheel ietsvan 'n legkaart vertoon" (1983: 327). Hy beskou dus die komplekse en interessante "Brontësque" narratiewestruktuur (wat in al bei dieromans geld) asook dietema van die inwerking van die verlede op die hede as 'n swakheid in die tweede roman. Laasgenoemdetema is egter ' $n$ besonder belangrike draad in Grovéseerkendeen bekroondeliterêreoeuvre. Heilna du Plooy sêbyvoorbeeld: “Diemeestevan [Grové se] verhaleen ook diedramas issterk gemoeid met dieverledeen dieinwerking van dieverledeop diehede" (1998: 483). In M eulenhof semense sêAnnemarie: "Ek sêjou mos: hier op Meulenhof is al wat tel diedingewat verby is" (63). O ok in hierdieaspek sluit al bei Grovéseliefdesverhaleby haar meer bekendeliterêrewerk aan.

Net soosin D ielaat lentevertoon M eul enhof se mense interessantesimbool patrone, ook ' $n$ "uiters hegtestrukturering van herhalende beeldeen motiewewaardeur die vertelling ' $n$ besonder digtesamehang en veelvlakkige betekenislaag vertoon" (kyk Roos 1998, hierbo) en weer eens is natuursimbole baiebelangrik. In die eerstebrief, skryf Annemarie byvoorbeeld vir Jan dat die beeldskone, verbitterde oujongnooi, Sarah Vermeulen (wat vyftien jaar tevore haar verloofdeMalan du Toit by diekansel verlaat het nadat sy uitgevind het hy het haar in 'n dobbelspel gewen) haar herinner aan 'n boom wat hulle saam in Julieby die ou pan gesien het:

... al wat takke was, was klipsteen gevries. Dit was baie mooi, daardie gestolde boom, ysig mooi, asof daar nooit iets anders was as die rypstil leegte nie. Maar ek kon dit nie verdra nie. Ek het sommer die perd se kop omgepluk en die wydtes ingejaag, weg uit daardie koue, blink wêreld. En toe ons later die vuur gepak het vir die koffie, het ek my hande styf gevou om die keteltjie (9). 
Later gebruik Sarah se suster, Nellie, dieselfde beeldpatroon om teenoor haar te protesteer oor die gedwonge maagdelikheid van die lewe op Meulenhof: "Van 'n boom wat nooit mag bot nie, moet jy geen vrug verwag nie" (17). Nelliewend haar weer tot die natuur se siklusse wanneer sy die emosionele vermorsing van die Vermeulen-susters se eensame lewe op Meulenhof onder die swaar hand van die verbitterde Sarah uitdruk:

Laat sy die geld hou - vir Meulenhof. Dis al waaraan sy dink: mure en gewels en dekriet, nuwe ruite en politoer en belastings [...] En waarvoor? Die bome word groen, en dan kom die somer, as jy weer kyk, lê die vallei wit van die kapok. En intussen skimmel ons weg (27).

Nog later keer Nellie weer terug na die boombeeld om die verwringing van hulle lewens deur Sarah se ongenaakbaarheid uit te beeld: “Dit laat jou skeef groei, so 'n soort lewe, altyd met die oog op 'n ander mens. Dis nes'n populierlat wat kleintyd gebuig word" (51). Uiteindelik keer Annemarieook terug na dieoorspronklikebeeld wanneer Sarah ten spytevan haarself reageer op Du Toitse liefdesverklaring: "Sy kyk nou na hom. Dis of sy effens oorbuig, en haar gesig word sag. Haar lippelag, en ek het gedink aan diever Karoopan daardie Julie-oggend, so witen klipsteen gevries, totdie son gekom het" (123). 'n Mens mag wel kritiseer dat Grovéhier amper diesimboliek vir dieleser uitlêingeval dieleser die betekenis dalk sou mis, maar dieselfdekritiek geld dikwels vir Charles Dickens, wat ook vir 'n populêregehoor geskryf het en wie se beroemde romans aanvanklik in tydskrifte as vervolgverhale verskyn het. Die verhaal boet aan aan subtiliteit, maar diefyn ontwikkeling van simbool patronedeur dieskrywer iswel 'n gegewe.

Net soos Grovéhaar narratiewe strategieas metafoor weergeein diebeeld van die legkaart, objektiveer sy ook die Gotiese storielyn in M eulenhof se mense in Pauline Vermeulen seborduurwerk:

As ek opkyk, sien ek Pauline se naald heen en weer beweeg. Dit is'n paneelstuk om te raam. Diekasteel met diebruin krummelmure is byna klaar. Op dieklein meertjie swem twee swane, en nou groei die minnaar met sy blou tuniek al uit die grysgeel materiaal. Die venster in die muur is nog 'n leë vierkant, maar juffrou Pauline het my al van haar vertel: die riddersvrou met haar bloedrooi roos wat daardeur gaan leun. Heerlik, Jan, om so 'n sprokieswêreld met jou naald te kan maak (28).

Dietoespeling is duidelik. Dievrou(e), Sarah en Nellie, is gevange in dieverbrokkelendekasteel van Meulenhof. Dieminnaar(s), Malan du Toiten Herman deConingh, beplan en wag vir die uiteindelike ineenstorting van die mure sodat hulleliefde in vervulling kan gaan. Dieswanesuggereer dieromantieseaanslag. Diestorielyn word dus deur middel van Pauline se borduurwerk as beeld in diestorie geobjektiveer. (Marlene van N iekerk gebruik in 2004'n soortgelyketegniek in A gaat wanneer sy met 
die doodskleed wat Agaat vir Milla borduur binne die roman 'n metafoor vir die roman self skep, deurdat Agaat in haar borduurwerk haar en Milla se verhaal op Grootmoedersdrift vasvang soos dieskrywer dit in woordkuns in dieroman gedoen het [vgl. Wessels 2006: 39].)

In hulleseminalefeministiese vertolking van Wuthering $\mathrm{H}$ eights en JaneEyrein die boek TheM adwoman in theAttic (1979), noem Sandra Gilbert en Susan Gubar vir N elly Dean, die sentral everteller in Wuthering H eights die "kunstenaar-verteller" (artistnarrator) wat uit hoofdevan haar kunstenaarskap 'n sterk oorlewingskrag het (Gilbert \& Gubar 1984: 290) en ander karakters manipuleer (292). Pauline Vermeulen is die kunstenaarsfiguur in M eulenhof semenseen uit dieuittreksel hierbo waarin dieroman met haar borduurwerk vergelyk word, en uit Annemarie se versugting oor hoe "[h]eerlik" dit moet wees "om so 'n sprokieswêreld met jou naald tekan maak" (28), is 'n metafiksioneleidentifisering van diekunstenaar Paulinemet dieskrywer (Grovél Joubert) nietevergesog nie. Dievreugdevan kunstenaarskap word duidelik in haar karakterisering weergegee:

Juffrou Pauline sit onder die lig; sy het haar borduurwerk by haar, en op haar skoot is die garing ' $n$ bont mengeling van koraalrooi en koningsblou en die silwergrys van 'n ver wolk. Sy steek die naald in en uit en trek die garing gelyk, weer in en uit, en oor die saai geel van die gespanne sy groei ' $n$ brug, 'n boom, 'n minnaar met sy luit, en juffrou Pauline lag sag (23).

Dit is dan ook diestil, innemende Pauline, die kunstenaar-skepper met dienodige oorlewingskrag, wat dieingrypende besluit neem om die huis af te brand sodat die verlede besweer en die susters bevry kan word uit die "kasteel met die bruin krummelmure" van Meulenhof waar hullesielkundig en emosioneel gevangegehou word: "'n Gebou is'n skamele ruil vir 'n vrou selewe," (96) isPaulinese opinie.

Die afbrand van Meulenhof en daarmee die susters se bevryding uit die verlammende, inperkendeverledebring ook eggo'suit dieAngel-Saksiesletterkunde. Dieooreenstemmendeafbrand van Manderley in R ebecca is reeds genoem. So brand dielerseherehuisDanielstown ook af aan dieeindevan Elizabeth Bowen sebekende modernistiese roman The Last September (1929) en bevry so die inwoners van die verlammendelas van dieverlede, sodat hulleas individueeerder as eksponentevan hulleklas- en rassegeskiedenis dielewekan aanpak. Dieoerteks is weer eens egter Jane Eyre. In hullegenoemdeinvloedrykevertolking van JaneEyre in TheM adwoman in the A ttic verduidelik Gilbert en Gubar hoe JaneEyreen Rochester vasgevang is in velepatronesoosman en vrou, baasen klaasen die prinsen Aspoestertjie(1984: 368), m.a.w. in dieVictoriaansekonvensies van klas en geslag. In M eulenhof semense is die karakters ook onderworpeaan hierdiesosialebeperkings, en in albei romansword dieswaar hand van dieverledeen die sosialestrukture deur die huis-Thornfield $\mathrm{Hall}$ in Jane Eyre en Meulenhof in M eulenhof se mense - versinnebeeld. Gilbert en 
Gubar (1984: 352-54) wys daarop dat Rochester en Jane Eyreinderwaarheid inherent gelykes is, en dat dieattraksie tussen hulleop hierdie werklikheid berus (Rochester noem Jane "my equal and my likeness" [Brontë2007: 252] as hy haar aanvanklik vra om tetrou), maar dat dieverhouding kritiek belemmer word deur die rolle waarin diesamelewing hulleplaas, versinnebeeld deur dieherehuisThornfield met Rochester se waansinnige vrou op die solder (vgl. Gilbert \& Gubar 1984: 337-71). Wanneer die huis afbrand en die waansinnige vrou wat die brand ook gestig het, sterf, word Rochester en Janesimbolies van diebeperkings bevry. Hullekan mekaar dan as gelykes in 'n nuwe lokaliteit, die minder indrukwekkende huis Ferndean, tegemoet gaan (vgl. Gilbert \& Gubar 1984: 368).

In dieKaapkolonievan 1904skep Grovéook'n milieu wat gekenmerk word deur diehiërargieseverdelingsvan klasen geslag. Diedilemma van dieVermeulen-susters op dieeensweel derige, nou verarmendelandgoed Meulenhof, isveral diedilemma van ontmagtigde vroue in die laat-Victoriaanse of Edwardiaanse tyd. Manlike dominansieword aangedui in Sarah senarratief van dieplaas segeskiedenis:

"Honderd en vyftigjaar, " antwoord sy stroef. "1754is die datum op diejaartal plaat.

Dit was Ewert Vermeulen wat eerste sy wa hier langs die stroompie uitgespan het.

Hy het die plaas aangelê. Hy het die opstal gebou, en van toe af het dit gegaan van

vader na seun, van die een Vermeulen na die ander" (95).

In hierdiegeslag is daar egter geen seun nie, en dit is die drie susters wat binne die onmoontlike beperkinge van dietyd oor wat behoorlik vir 'n beskaafdedame is om aan te pak, die plek aan diegang moet hou. AsN elliekla oor alles wat in hierdiestryd ingewerp word, is dit die ontoereikendeaard van aktiwiteite wat as geskik vir dames beskou is, wat sy noem: "Van Januarie tot Desember is dit 'n blink stroom in 'n bodemlose put: oulappeen trippenseen daalders, elke pennie wat ons inkry - jou borduurgeld, myne vir musiek" (27), en die dorpskinderbek voeg daaraan toe: “Die skoen knyp daar, hy knyp al lankal, van die tyd dat Pauline met die borduurlesse begin het en Nellie kamtig vir 'n paar dogtertjies begin help het met musiek" (19). Wanneer Andries N ordien aan Sarah die noodsaak van die verkoop van die ewe vername N ordienshalte aan die gehate Malan du Toit verduidelik, is daar weer 'n toespeling op diebeperkingswat geslag op dieVermeulen-susterslê: "Jy verstaan nie, Sarah. Hy wil tweeduisend pond gee. Vrouens weet nievan sulkedingenie" (44). In 'n artikel oor die neo-Gotiek op Litnet (2010) meld Hennie Aucamp dat verset teen paternal isme diésubgenrekenmerk, aangesien vroue hullesteedsin diemoderne samelewing as gevangenesin hulle "kastele" (van sosialenorme) bevind.

Diegeslagshiëragietussen Malan du Toit en Sarah Vermeulen word (soos in J ane Eyre) versterk deur diemeegaandeekonomiesehiërargie: met diegeld wat hy in die diamantveld gemaak het, ishy dieryksteman in dieomgewing, terwyl dieVermeulens sukkel om liggaam en siel op 'n beskaafde wysebyeen tehou. Interessant keer Grové 
egter die klassehiërargie om: Malan du Toit kom uit 'n nederige agtergrond en het hom self tot ' $n$ ryk man opgewerk, terwyl die Vermeulen-susters van een van die oudsteen mees gerespekteerdeen gesofistikeerdefamilies in die omgewing afstam. Die Vermeulen-susters se vader trek reeds die klasselyne wanneer Du Toit vir die eerstekeer in dieStangwêreld aankom:

"Dis'n mooi wêreld, " het Vader gesê, "almal die ou familieplase en lank gevestig."

"Ja, " het [Malan du Toit] geantwoord, "dis 'n mooi wêreld, maar na my smaak te klein en te vervelig, en dan die berge [...] Dis te nou, " en hy skud sy kop ongeduldig. "Daar waar ek vandaan kom..."

“Ja, “ waar jy vandaan kom [...] paddastoele is glo volop daar, veral ná 'n donderstorm" (31).

Du Toit word daarnain gesprekkemet dieVermeulensherhaal delik met'n paddastoel vergelyk. Hy word ook deur Sarah Vermeulen "'n fortuinsoeker" en "agteraf delwer" (44) genoem. Du Toit noem later self "dietweehonderd jaar wat nog altyd tussen ons was, dieslangkop self" (110). Afgesien van dieklassespanning tussen dietweefamilies, skep Grovéhier 'n breër simboliesespanning tussen diehoogsontwikkelde, verfynde, maar dekadente lewenswêreld van die lank gevestigde Kaap teenoor die minder verfynde, maar gesonder lewenskragtigheid van dielater gevestigde binneland. Dit komneer op ' $n$ toespeling deur Grovéop diekarakterisering, deur bv. dieAmerikaanse romansiers Henry James en F. Scott Fitzgerald, van dielank gevestigde Ooskus van Amerika as beskaafd maar dekadent (met Europa, nog verder Oos, as diehoogtepunt van dekadensie), teenoor dieWesteasnuut, robuusen lewenskragtig, 'n deurlopende temain veral James sewerk. Hierdiespanning word nog 'n patroon wat dieskryfster fyn uitborduur in die loop van die roman. In antwoord op meneer Vermeulen se belediging antwoord Malan du Toit:

Ons eet daar sommer uit blikborde, en as daar water naby is, maak ons 'n bakkie met ons hande; daar's nie tyd vir tierlantyntjies nie. Maar as ons iets wil hê, betaal ons daarvoor, sommer kontant, al ruik die munt na saalsak. En dis meer as wat die mense van die Stangwêreld kan sê (31).

Ten spytevan sy hoogmoed, erken ou meneer Vermeulen later self dieverval van sy klas wanneer dieN ordiens hullegevestigde plaas aan Malan du Toit verkoop:

“'Andries N ordien kan nie anders nie, hy's klaar. Die ou families van die Stangkom sal dieeen ná die ander gaan,' en hy kyk naM eulenhof en dielande. 'Dieeen nadie ander'" (66).

Soos in JaneEyreis ditegter duidelik dat Malan du Toiten Sarah Vermeulen as geskikte en gelykevennotevir mekaar bedoel is. Dit is nieSarah sestand wat Malan du Toitna haar aantrek nie, maar afgesien van haar skoonheid is ditjuishaar trots, haar doelgerigte 
vasberadenheid en hardgebaktheid, eienskappewat sy met hom deel, wat haar vir hom onweerstaan baar maak. Wanneer sy uiteindelik sy hofmakery haar laat welgeval - voor sy van die dobbelspel uitvind - fluister Du Toit teenoor haar: “N ie'n delwer en 'n diamantgrawer nie, nè?' [...] “Nie'n Kimberleysetransportryer nie, nè?" [...] “M aar jy gee nie om om hom te gebruik nie, nè, soos ' $n$ mens ' $n$ vloermat in die reënwater gebruik [...] M aar hierdie keer is jy verkeerd, Sarah." [...] "Dis soos dit hoort, my liefling," sêhy uiteindelik. "Diswatjy gekry het" (92). Hy beklemtoon hier dieonafwendbaarheid van hulleverhouding as gelykevennote.

Die "slangkop" van klas bly egter 'n strydpunt en na Sarah uitgevind het dat Du Toit haar in 'n dobbelspel teen haar verloofdeN ordien - sóóssy ' $n$ lid van een van die ou Stangkom-families- gewen het, draai sy haar rug onverbiddelik teen die delwer. Sy wy haar toeaan Meulenhof, simboliesvan dieVermeulens searistokratieseverlede, en alles- ook haar en haar susters sekanseop persoonlikegeluk - word ondergeskik gestel aan die instandhouding van hierdie glansryke monument. Wanneer Nellie verlief raak op Malan du Toit seTransvaalse nefie, Herman deConingh, bly Sarah onverbiddelik teen so 'n alliansie gekant. Dit is tekenend dat wanneer Nellie vir Herman aan haar susters wil voorstel, dit diehuis is wat haar afskrik: "M aar toeons nader aan Meulenhof kom en ek diegewels en bomesien, was dit of ek lam geword het. Byna met trane in my oë het ek hom gevra om nie saam te kom nie" (53). In 'n kritiekekonfrontasieoor diesaak tussen Nellie, Sarah, Herman deConingh en Malan du Toit is dit weer die huis wat deurslaggewend blyk, met Sarah as diedoodsengelbewaker van hierdiesimbool van 'n elegantemaar verstikkendeverlede:

"Ek kom nie weer terug nie, Nellie. “ Dit was Herman. Ek het geweet dat dit die eindewas, maar sy my suster, was so bleek en so alleen [...] en dan die huis [...] nes of dit gewag het (58).

Nellieis byna onmiddellik spyt oor haar inskiklikheid en word verbitterd teenoor beide Sarah en die huis: "Vandag nog kan ek nie die reuk van vars gekalkte mure verdra nie. Dis vir my nes daardieoggende in diestil, skoon huis" (58).

Dit is diekunstenaar Paulinewat die dodelikeaard van dieMeulenhof-kultus by Sarah insien en besluit om iets daaraan te doen, en dit is eers as M eulenhof totaal afbrand dat dieVermeulen-susters bevry kan word van hulleverlammende, glansryke verledeen Sarah asgelyke vennoot en minnaar Malan du Toit tegemoet kan gaan. Dit is betekenisvol dat al bei diebevrydepare, Nellieen Herman deConingh en Sarah en Malan du Toit, die ou, verfynde maar dekadenteKaapse vallei verlaat om 'n nuwe toekoms in dieongerepte $\mathrm{N}$ oordete gaan vestig, $\mathrm{N}$ elliein diehuis met groot stoepe en selonsrose, lemoenbloeiselsen vyebomeop 'n tabakplantasieby Pietersburg waarna sy sedert haar eersteverhouding met Herman agtjaar vroeër hunker, terwyl Sarah in dieasse van Meulenhof vir Malan sêdat hullena dieOnderveld toemoet gaan, "na jou wêreld toe, daar in die wye vlaktes" (127). Op hierdie wyse word beide die 
tradisionelevoorstelling van dieherehuis as sinnebeeld van ' $n$ belasteverledein die tradisievan Brontë, Bowen en Du Maurier, sowel as diejamesiaanseopposisietussen dekadente ou wêreld jeens lewenskragtige nuwe, vernuftig deur die skryfster tot simboliesevoltooiing gebring.

Die roman het grootliks 'n koorsagtige Gotiese intensiteit wat soms oorhel na melodrama en herinner in dieopsig ook aan Wuthering $\mathrm{H}$ eights en delevan J ane Eyre. Die atmosfeer van onderdrukteemosie en erotiek in 'n gesin van vrouewat onder gedwongegeslagsonthouding lewe, herinner ook aan dieSpaansedigter en dramaturg Federico García Lorca se toneelstuk D ie huis van Bernarda A lba - in Spaans L a casa de Bernarda A lba (1936) - wat in 1947 in Engels vertaal is. Veral N ellie se onderdrukte emosiewat haar met witgesig en bewendehande(16) haar minnaar senaamlaat sêen “soos'n warrel wind" diegang laat afstorm (18), wat in histeriese lagbuie uitbars (24, 27) en huil en lag deurmekaar (46) herinner aan Adela, die hartstogtelike jongste dogter in die onderdrukte, swartgallige Alba-huishouding. Tog onderspeel die skryfster hierdie element van dramatiese intensiteit in dieslot wanneer Sarah ná die drama van Meulenhof se brand op M alan du Toit seopmerking dat hullenog ver het omtegaan, die roman met dieamper verspottewoorde, "Ja, [... ] oor die berg en ver, ver weg" ${ }^{2}$ afsl uit. Dit is'n lughartigeverwysing na'n tradisioneleEngelsevolkswysie en dietoon kom strydig voor met Sarah sekarakter deur dieloop van dieroman. Dit is asof dieskryfster met dieslot aandui dat sy niehaar eieroman ernstig opneem nie. Dié indruk sluit dan ook aan by die beskrywing van haar alter ego in die verhaal, juffrou Pauline, wat saggies "lag” terwyl sy haar Gotiesetapisserievoltooi (23). Dit lyk asof dieskryfster dit vir 'n oomblik laat deurskemer dat hierdieverhaal bloot vir die pret (en "om den brode" soossy dit later sou uitdruk) geskryf is. Dit bring onsterug by diekwessieoor hóéernstig hierdietweeLindaJoubert-romansdan literêr aangeslaan kan en behoortteword.

In haar gepreek met Elize Botha in 1973, het Henriette Grové toegegee dat die "gewraaktenovelles" ${ }^{3}$, M eulenhof se mense en D ielaat lente "moontlikhede" gehad het (61), maar verduidelik dat die skrywer in die soort populêreliefdesverhale' $n$ soort "verraad" teenoor'n verhaal pleeg wanneer dieverhaal seeiedinamikaen dieinherente vereistes vir dieafloop en ontknoping deur dieskrywer geïgnoreer word omdat die populêre verhaal-konvensie eis dat dieleser tevrede gestel moet word: "Jy sien wel dat daardie probleem of daardiesituasie waaruitjy jou verhaal laat ontstaan, eintlik dwingend op ' $n$ bepaalde manier opgelos moet word, maar dan pleeg jy verraad teenoor diewéét, en jy geehom'n romantiesedraai" (Botha 1973: 62). Dieverloop van dieverhaal word dus'n soort "leuen" teenoor dieartistieke "waarheid" soos deur die betrokkeskrywer ervaar. In D ie kêrel van die Pêrel, wat tien jaar na die gesprek met Botha verskyn het, gaan dit soos vroeër vermeld juisomtrent dieverhouding tussen waarheid en leuen. Die jong Elwiena het 'n behoefte aan 'n droomwêreld as ' $n$ ontvlugting van 'n onaangenamewerklikheid, maar leer deur bittereervaring dat die 
verleiding van dieleuen bedroewendegevolgekan hê. Daarnavolg sy onverbiddelik diewaarheid maar vind dat dit ook totongeluk lei en aan dieeindevan dieverhaal besef sy dat ' $n$ mens soms dieleuen nodig het om die bittere waarheid van bestaan oorleefbaar temaak. Ek wil aanvoer dat wat Grovéas die romantiese "leuen" in die twee romans beskou het, in dieselfde lig gesien kan word. Die verhaal is binne' $n$ sekereliterêrekonvensiegegiet en dit bring kompromieëmee. Hierdiekompromieë is egter dwingend in terme van die appèl van die gekose genre wat sy eie plek as ontvlugtingsletterkunde binne die breëraamwerk van dieliteratuur het. Sedert die negentigerjareis daar' $n$ groter openheid totalternatiewegenres soos diespeurverhaal en dieliefdesverhaal en het diekloof tussen dieliterêreen die populêrevervaag, al het dit nieverdwyn nie. Wanneer 'n liefdesverhaal met soveel literêre vaardigheid, artistieke bedrewenheid en indrukwekkendeverwysingsreikwydtegeskryf word as wat dit met die twee Linda Joubert-romans die geval is, is dit na my mening - ten spytevan dieskrywer seeievoorbehoude in diesewentigerjare- vandag wel gerade om die betrokkewerke letterkundig te ondersoek en by dieskrywer seoeuvre in te skat. HenrietteGrovéhoef haar geensins vir LindaJoubert teskaam nie.

\section{Aantekeninge}

1. In haar gesprek met Elize Botha noem Grové Jane Austen as een van die gunsteling-skrywers uit haar jeug: "My pa het ' $n$ redelike goeie versameling boeke gehad, heelwat negentiende-eeuse Engelse romans - Jane Austen veral, en ek het haar werk met eindelose plesier oor en oor gelees" (Botha 1973: 67).

2. "Over the hills and far away", 'n volksliedjie waarvan een weergawe in John Gay se populêre Beggar's O pera (1728) opgeneem is.

3. Hoewel Botha die twee werke in haar gesprek met Grové "novelles" noem en Grové daarby inval, verwys die meeste kritici (bv. J. C. Kannemeyer, Heilna du Plooy, Annemarie van Niekerk) na die werke as "romans". Ek het by hierdie meer algemene gebruik gebly. Die verhale is ook elk as 'n "volledige roman" in die Sarie M arais aangebied, M eulenhof se mense in 'n enkele uitgawe (18 April 1956) en Die laat lente in twee opeenvolgende uitgawes (4 en 18 September 1957), en nie as vervolgverhale soos heelwat kritici meen nie.

\section{Bronnelys}

Aucamp, Hennie. 2010. Neo-Gotiek in dieAfrikaanseletterkunde. Litnet. 12Augustus. < www.litnet.co.za/ cgi-bin/giga.cgi?cmd=cause_dir_news_item\&cause_id=1270\&news_id=91178> Besoek September 2010.

Botha, Elize. 1973. Henriette Grové in gesprek met Elize Botha. Gesprekke met Skrywers 3. Kaapstad: Tafelberg.

Botha, Elize. 1987. Prosakroniek. Kaapstad: Tafelberg.

Bowen, Elizabeth. 1952 [1929]. The Last September. Harmondsworth, Middlesex: Penguin.

Brontë, Emily. 1940 [1847]. Wuthering H eights. London: Classics Book Club.

Brontë, Charlotte. 2007 [1847]. Jane Eyre. Richmond, Surrey: Oneworld Classics.

Cilliers, Stoffel. 2009. Storielyn onwaarskynlikhede kelder verhaal. [Resensie: D ie laat lente deur Linda Joubert]. D ie Volksblad, 16 Junie. <http://152.111.11.6/argief/berigte/volksblad/2009/06/15/VB/8/ bklaatlente.html> Besoek September 2010.

Du Maurier, Daphne. 1938. Rebecca. London: Gollanc. 
Du Plooy, Heilna. 1998. Henriette Grové. In H. P. van Coller (red.). Perspektief en profiel 1. Pretoria: J. L. van Schaik, 475-88.

Eliot, T. S. 1969. The Complete Poems and Plays of T. S. Eliot. London: Faber.

Grové, Henriette. 1966. Jaarringe. Kaapstad: Tafelberg. 1983. Die kêrel van die Pêrel. Kaapstad: Tafelberg. 1989. In die kamer was 'n kas. Kaapstad: Tafelberg.

Gilbert, Sandra M. \& Gubar, Susan. 1984 [1979]. The M adwoman in the Attic. New Haven \& London: Yale University Press.

Hambidge, Joan. 2008. M eulenhof se mense na jare steeds'n lofwaardige teks. Litnet. 24 Okt. <www.litnet .co.za/cgi-bin/giga.cgi?cmd=cause_dir_news_item\&news_id =54763\&cause_id=1270> Besoek September 2010.

Jooste, Ena. 1975. Syn en skyn as aspekte van die epiek van Henriette Grové en Chris Barnard. Ongepubliseerde M.A. verhandeling, Potchefstroomse Universiteit vir Christelike Hoër Onderwys.

Joubert, Linda. 1962. Roosmaryn en wynruit. Pretoria: HAUM.

2008 [1961]. M eulenhof se mense. Kaapstad: Human \& Rousseau.

2009 [1962]. Die laat lente. Kaapstad: Human \& Rousseau.

Kannemeyer, J. C. 1965. Die stem in die literêre kunswerk. Kaapstad: Nasou. 1983. Geskiedenis van die Afrikaanse Literatuur II. Pretoria: Academica.

Lorca, Federico García. 1980. Die huis van Bernarda Alba. Vert. Uys Krige. Kaapstad: Tafelberg.

M.E. R. 1927. O nweershoogte en ander verhale. Kaapstad: Nasionale Persboekhandel. ; Rousseau, Ina; Eybers, Elisabeth \& Grové, Henriette. 1957. Kwartet. Kaapstad: Nasionale Boekhandel.

Montgomery, L. M. 1949 [1936]. Anne of Windy Willows. London: George G. Harrap.

Rademeyer, Alet. 2009. Skrywer Henriette Grové sterf, in Beeld, 16 Desember. <http://152.111.1.88/argief/ berigte/beeld/2009/12/17/B1/3/targrove.html> Besoek September 2010.

Rhys, Jean. 2000 [1966]. Wild Sargasso Sea. Londen: Penguin.

Roos, Henriette. 1998. Perspektief op die Afrikaanse prosa van die twintigste eeu. In H. P. van Coller (red). Perspektief en profiel 1. Pretoria: J. L. van Schaik, 21-117.

Van Niekerk, Annemarié. 1999. Die Afrikaanse vroueskrywer - van egotekste tot postmodernisme (18de eeu - 1996), in Perspektief en profiel 2. In H. P. van Coller (red). Pretoria: J. L. van Schaik, 305-443.

Van Niekerk, Annie. 1946. M et liefde van Katinka. Kaapstad: Nasionale Persboekhandel.

Van Niekerk, Marlene. 2004. A gaat. Kaapstad: Tafelberg.

Webster, Jean. 1958. Vadertjie Langbeen. Vert. W. O. Kühne. Die Libri-reeks. Pretoria: J. L. van Schaik.

Wessels, Andries. 2006. Marlene van Niekerk se Agaat as inheemse Big House-roman, in Tydskrif vir Letterkunde, 43(2): 31-45.

Yardley, Jonathan. 2004. Du Maurier's R ebecca, a worthy ‘Eyre’ apparent. Washington Post, 16 March, C01. 